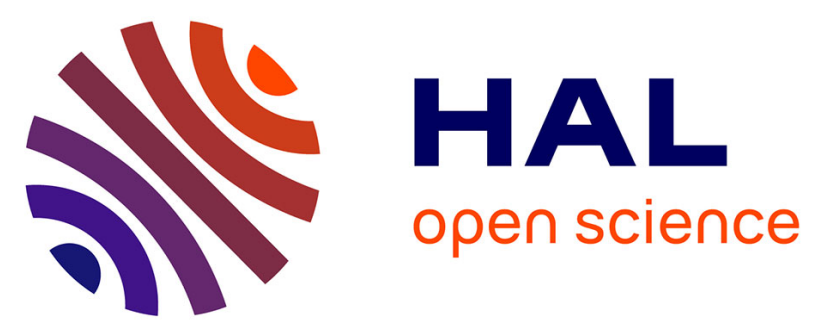

\title{
Epidemiologically and clinically relevant Group B Streptococcus isolates do not bind collagen but display enhanced binding to human fibrinogen.
}

Shaynoor Dramsi, Eric Morello, Claire Poyart, Patrick Trieu-Cuot

\section{To cite this version:}

Shaynoor Dramsi, Eric Morello, Claire Poyart, Patrick Trieu-Cuot. Epidemiologically and clinically relevant Group B Streptococcus isolates do not bind collagen but display enhanced binding to human fibrinogen.. Microbes and infection / Institut Pasteur., 2012, 14 (12), pp.1044-8. 10.1016/j.micinf.2012.07.004 . pasteur-01300174

\section{HAL Id: pasteur-01300174}

\section{https://hal-pasteur.archives-ouvertes.fr/pasteur-01300174}

Submitted on 8 Apr 2016

HAL is a multi-disciplinary open access archive for the deposit and dissemination of scientific research documents, whether they are published or not. The documents may come from teaching and research institutions in France or abroad, or from public or private research centers.
L'archive ouverte pluridisciplinaire HAL, est destinée au dépôt et à la diffusion de documents scientifiques de niveau recherche, publiés ou non, émanant des établissements d'enseignement et de recherche français ou étrangers, des laboratoires publics ou privés. 


\title{
Epidemiologically and clinically relevant Group B Streptococcus isolates do not bind collagen but display enhanced binding to human fibrinogen
}

\author{
Shaynoor Dramsi ${ }^{\mathrm{a}, \mathrm{b}, *}$, Eric Morello ${ }^{\mathrm{a}, \mathrm{b}}$, Claire Poyart ${ }^{\mathrm{c}, \mathrm{d}, \mathrm{e}}$, Patrick Trieu-Cuot ${ }^{\mathrm{a}, \mathrm{b}}$ \\ a Institut Pasteur, Unité des Bactéries Pathogènes à Gram positif, 75015 Paris, France \\ ${ }^{\mathrm{b}}$ Centre National de la Recherche Scientifique (CNRS) ERL 3526, Paris, France \\ ${ }^{\mathrm{c}}$ Institut Cochin, Université Sorbonne Paris Descartes, Faculté de Médecine CNRS (UMR8104), 75014 Paris, France \\ ${ }^{\mathrm{d}}$ Institut National de la Recherche et de la Santé Médicale, U1016, Paris, France \\ ${ }^{\mathrm{e}}$ Assistance Publique Hôpitaux de Paris, Service de Bactériologie, Centre National de Référence des Streptocoques, Hôpital Cochin, Paris, France
}

Received 23 March 2012; accepted 2 July 2012

Available online 24 July 2012

\begin{abstract}
Group B Streptococcus (GBS) is the leading cause of neonatal septicemia and meningitis. Pili appendages were shown to play a critical role in bacterial adhesion and colonization of human tissues. Recently it was claimed that binding of the pilus-associated adhesin PilA to collagen is a critical, initial step in promoting interactions with the $\alpha 2 \beta 1$ integrin expressed on brain endothelial cells. Here we show that strain NCTC10/84 used in this study is not representative for GBS isolates and question the importance of collagen as a critical extracellular matrix component for GBS infections of the central nervous system.
\end{abstract}

(C) 2012 Institut Pasteur. Published by Elsevier Masson SAS. All rights reserved.

Keywords: GBS; Streptococcus; Pili; Collagen; Meningitis

\section{Introduction}

Streptococcus agalactiae (also known as Group B Streptococcus, GBS) is the leading cause of neonatal infections in the industrialized world. The first systematic review and metaanalysis of neonatal Group B Streptococcal disease shows that five serotypes (Ia, Ib, II, III and V) are responsible for the global burden of disease [1]. Among those, serotype III is of major importance in neonatal diseases whereas serotype $\mathrm{V}$ is mainly involved in adult invasive diseases. Several epidemiological studies, including a recent report from our laboratory [2], pinpoint a single GBS clone of capsular serotype III, designated ST17 according to its sequence type (ST) as being responsible for the vast majority $(>80 \%)$ of meningitis cases [3-8]. The ST17 clone is now worldwide referred to as the hypervirulent GBS clonal complex 17 (CC-17) and $\mathrm{COH} 1$,

\footnotetext{
* Corresponding author. Institut Pasteur, Paris, France. Tel.: +33 (0)1 4438 94 87; fax: +33 (0)1 45688938 .

E-mail address: shaynoor.dramsi@pasteur.fr (S. Dramsi).
}

a representative strain of this group, has been sequenced recently [9].

Surface-exposed pili has emerged as appealing host colonizing factors as well as vaccine antigen candidates. We and others have initially characterized pili in $S$. agalactiae [10-12] and have demonstrated their role in adhesion to host cells and in biofilm formation. Two genomic pilus islands (PI1 and PI-2) have been identified in GBS. Of note, the PI-2 locus exists in two variant forms: PI-2a (73\%) being present in the vast majority of GBS strains belonging to all serotypes and PI-2b (27\%) being restricted to ST17 and a few other clinical isolates. The overall organization of each PI locus is similar as it contains three genes that encode cell wall anchored LPXTG proteins and two genes encoding class C sortases involved in pilus assembly. The PI-2a pilus is composed of the major backbone protein (PilB) decorated with the tip adhesin (PilA) and attached to the bacterial cell wall with the pilus-anchoring subunit (PilC) $[10,13]$. In nonST17 strains, lack of PilA was associated with a significant decrease in the ability of bacteria to bind to human epithelial 
$[10,14]$ as well as to endothelial (hBMECs) cells [15]. Interestingly PilA contains a Von Willebrand type A factor domain (VWA), a domain known to tightly bind to collagens present on the vessel wall and to control platelet adhesion to the damaged vasculature. This VWA was shown to be mandatory for adhesive properties of PilA [14]. A recent report from Banerjee et al. proposed that binding of the pilus-associated adhesin PilA to collagen is a critical initial step in promoting interactions with the $\alpha 2 \beta 1$ integrin expressed on brain endothelial cells. Activation of this host receptor was reported to cause focal adhesion kinase (FAK) activation and downstream phosphatidylinositol-3 phosphate kinase (PI3K) and MAPK signaling, resulting in host chemokine expression and neutrophil recruitment during infection and bacterial entry into the central nervous system (CNS) [16]. Banerjee et al. have used the GBS strain NCTC10/84 which is a clinical isolate of capsular serotype $\mathrm{V}$, a serotype not normally associated with meningitis. On the other hand, Al Safadi et al. proposed that human fibrinogen is the extracellular matrix (ECM) component critical for CNS infections caused by CC17 isolates [17]. In this brief report, we tested the binding capacity of randomly selected clinical GBS isolates to bind to collagen and fibrinogen. Our results question the choice of GBS strain NCTC10/84 as a relevant representative to study GBS-host interactions, in particular CNS invasion.

\section{Material and methods}

\subsection{Bacterial adherence to ECM components}

GBS and Streptococcus gallolyticus were grown in ToddHewitt (TH) broth whereas recombinant Lactococcus lactis was grown in M17 1\% glucose containing erythromycin at $5 \mu \mathrm{g} / \mathrm{ml}$. Polystyrene 96-wells plates (NUNC) were coated with collagen I (from rat tail, BD Biosciences) or collagen IV (from human cell culture, Sigma-Aldrich C6745) at $50 \mu \mathrm{g} / \mathrm{ml}$ (100 $\mu \mathrm{l}$ per well) and incubated overnight at $4{ }^{\circ} \mathrm{C}$. After saturation of non-specific sites with Superblock Buffer (Thermo Scientific), approx. $10^{8}$ bacterial colony forming units (cfu) were added and the plates were incubated for $2 \mathrm{~h}$ at $37{ }^{\circ} \mathrm{C}$. Non-adherent bacteria were removed using the ELx50 Microplate Strip Washer (BioTek). Adherent bacteria were stained with $0.1 \%$ crystal violet for $30 \mathrm{~min}$, washed twice with PBS, and air-dried for $15 \mathrm{~min}$. The stained bacteria were resuspended for quantification in ethanol/acetone (80:20). The plate was scanned and absorbance at $595 \mathrm{~nm}$ was measured. Similar experiments were performed with human fibrinogen purchased from Sigma-Aldrich (from human plasma F3879).

\subsection{Hemolysin assay}

Approximately $2 \times 10^{8} \mathrm{cfu}$ of GBS cells were collected from liquid cultures at exponential phase, washed once with phosphate-buffered saline (PBS), and resuspended in $1 \mathrm{ml}$ of PBS containing $0.2 \%$ glucose. Serial dilutions (2-fold) of this suspension in PBS containing $0.2 \%$ glucose were mixed with an equal volume of $1 \%$ sheep erythrocytes (RBC) in the same buffer and incubated at $37{ }^{\circ} \mathrm{C}$ for $1 \mathrm{~h}$. After incubation, unlysed RBC and bacteria were removed by centrifugation and hemoglobin content of the supernatant was assessed by measuring absorbance at $420 \mathrm{~nm}$ (A420). The hemolytic titer of each strain was determined as the reciprocal of the greatest dilution producing $50 \%$ hemoglobin release compared to control samples in which all RBC were lysed by sodium dodecyl sulfate (SDS 0.2\%).

\section{Results and discussion}

\subsection{Binding of clinical GBS isolates to collagen and fibrinogen}

We investigated the ability of 20 GBS strains isolated from invasive neonatal disease (10 non-ST17 and 10 ST17 strains that were randomly selected) to bind to collagen type I, type $\mathrm{IV}$, and fibrinogen. We found no significant binding to collagen I and IV as compared to the positive control S. gallolyticus, a collagen-binding species causing endocarditis [18] (Fig. 1A and data not shown). Furthermore, recombinant strains of L. lactis overexpressing either PilA or the entire PI2a pilus of GBS strain NEM316 did not bind to collagen I or IV, unlike L. lactis overexpressing the collagen-binding Pill of S. gallolyticus (Fig. 1A and data not shown). These results indicate that the PilA protein is most likely not directly responsible for collagen binding.

In contrast, all $20 \mathrm{GBS}$ strains were able to bind to human fibrinogen at various levels in a dose-dependent manner. All ST17 isolates displayed higher binding as compared to nonST17 strains (Fig. 1B). The representative assay shown in Fig. 1B was conducted as blind test. The isolates marked by an asterisk were predicted as being ST17 strains based on their increased fibrinogen binding phenotype. This prediction was later indeed confirmed to $100 \%$. These results are in perfect agreement with a recent study [17] suggesting that the higher fibrinogen binding ability of CC-17 strains may participate in their enhanced invasiveness for neonates as compared to strains of other CCs.

\subsection{GBS strain NCTC10/84 is an atypical clinical isolate}

The GBS strain NCTC10/84 (also called 1169-NT1) is of capsular serotype $\mathrm{V}$ and was isolated from blood of a septic neonate [19]. Its genome has not been sequenced yet. We determined that strain NCTC10/84 belongs to the ST-26 (http://pubmlst.org/sagalactiae/), a worldwide very rare sequence type $[20,21]$ although it is representing $15 \%$ of GBS isolates from the Central African Republic and Senegal [22].

It is interesting to note that Doran et al. previously reported that the beta-haemolysin/cytolysin $(\beta-h / c)$ of GBS activates specific signaling pathways in human brain microvascular endothelial cells (HBMEC) resulting in IL-8 release, neutrophil recruitment and enhanced virulence [23]. The $\beta-\mathrm{h} / \mathrm{C}$ toxin was identified as the principal factor responsible for blood- 

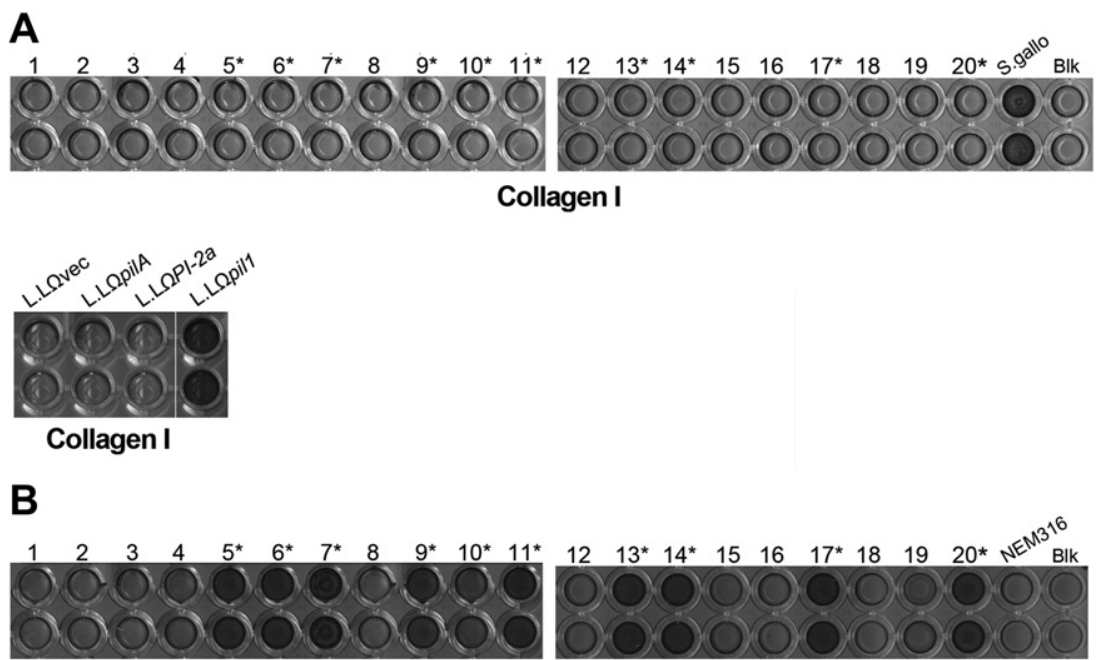

Human Fibrinogen

Fig. 1. A - Adherence of GBS wild type strains and Lactococcus recombinant strains to immobilized collagen I (Col I). Microtiter wells were coated with $5 \mu \mathrm{g}$ of $\mathrm{Col} \mathrm{I}$ and $10^{7} \mathrm{cfu}$ were added. Adherent bacteria were detected using crystal violet staining. The two horizontal rows represent sample duplicates. Upper panel -20 GBS neonatal isolates 10 of which are ST17* and 10 non-ST17 (for details see Table 1). Streptococcus gallolyticus (S. gallo strain UCN34) is used as positive control. Lower panel - Adherence of L. lactis NZ9000/pOri23 and its various derivatives. Similar results were obtained with human collagen IV (not shown). B - Adherence of GBS wild type strains to immobilized human fibrinogen $(3 \mu \mathrm{g}$ per well).

brain barrier activation triggered by the GBS strains A909, $\mathrm{COH} 1$, and NCTC10/84. We thus compared the hemolytic activity of the seven sequenced GBS strains (NEM316, 2603V/R, A909, COH1, H36B, 515, and 18RS21) and 20 additional GBS isolates from neonatal disease that we have previously used [2]. Most clinical isolates belonging to different ST groups, including ST17, were less hemolytic than our reference strain NEM316 WT (Fig. 2, Table 1). The hemolysin-negative mutant NEM316 $\Delta c y l E$ and the hyperhemolytic mutant NEM $316 \Delta \operatorname{cov} S R$ were used as negative and positive controls, respectively. Strikingly, GBS NCTC10/84 appeared to be as hemolytic as the hyperhemolytic mutant NEM316 $\Delta \operatorname{cov} S R$ (Fig. 2B, Table 1). In view of these two relevant characteristics i) the epidemiological rarity and ii) a hyperhemolytic phenotype, we conclude that NCTC10/84 is an atypical GBS strain.

In conclusion, the role of the PilA-collagen interaction in the process of CNS invasion by GBS is questionable. We suggest that the unusual hyperhemolytic phenotype of GBS strain NCTC10/84 impacts on the cellular and host responses described in the report by Banerjee et al., precluding any definitive conclusion about the role of the pilus-associated adhesin PilA. The many roles uncovered for GBS pili including bacterial adherence to host cells, biofilm formation, and virulence were attributed to the PI-2a pilus. Importantly, the ST17 hypervirulent clone contains two other pilus loci, PI1 and PI-2b, whose function(s) remains unveiled. The elucidation of their role is the subject of our ongoing investigations.
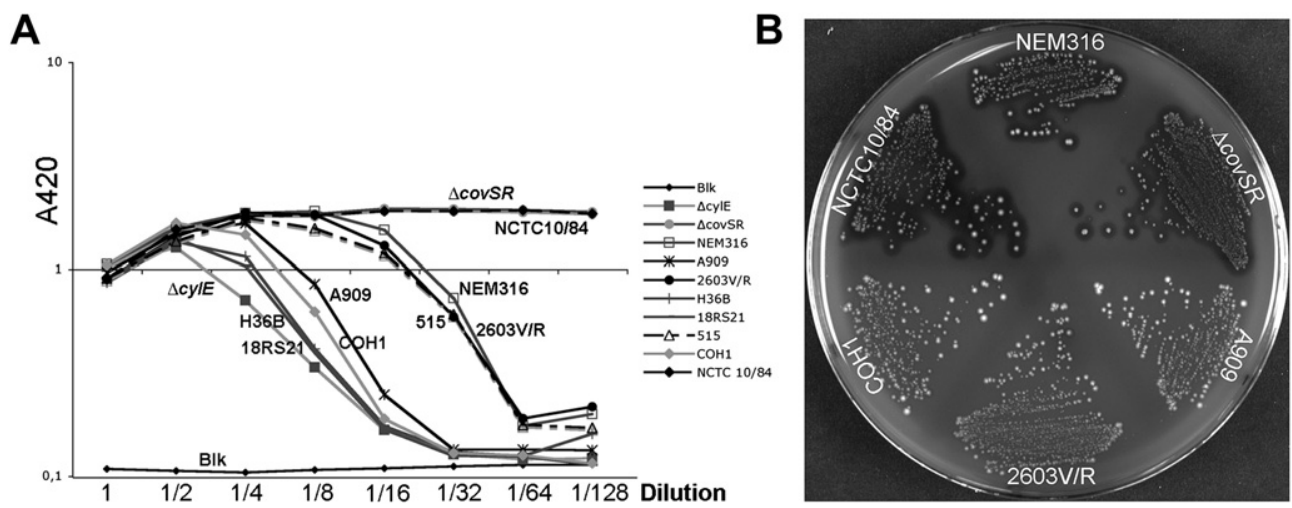

Fig. 2. Hemolytic activity of sequenced GBS strains. The hemolysin-negative mutant $\Delta c y l E$ and the hyperhemolytic mutant $\Delta$ covSR derived from our reference strain NEM316 were used as negative and positive controls, respectively. A - Hemoglobin release in supernatants quantified by absorbance measurement $\left(\mathrm{A}_{420}\right)$. $\mathrm{B}$ - GBS streaking on horse blood agar plate. The data shown here are representative of at least three independent experiments. 
Table 1

Main characteristics of the clinical GBS isolates used in this study.

\begin{tabular}{|c|c|c|c|c|c|}
\hline GBS strains & Capsular serotype & ST cluster & Type of neonatal infection & Hemolytic index (relative value) & Col I or IV binding \\
\hline \multicolumn{6}{|l|}{ Clinical isolates } \\
\hline 1 & II & 28 & EOD/bacteremia & $16-32$ & - \\
\hline 2 & Ia & 23 & EOD/meningitis & 8 & - \\
\hline 3 & Ia & 23 & EOD/bacteremia & 8 & - \\
\hline 4 & Ia & 23 & EOD/bacteremia & $4-8$ & - \\
\hline 5 & III & 17 & LOD/meningitis & $4-8$ & - \\
\hline 6 & III & 17 & LOD/meningitis & $16-32$ & - \\
\hline 7 & III & 17 & LOD/meningitis & $8-16$ & - \\
\hline 8 & Ia & 24 & EOD/bacteremia & $8-16$ & - \\
\hline 9 & III & 17 & EOD/bacteremia & $4-8$ & - \\
\hline 10 & III & 17 & LOD/meningitis & 4 & - \\
\hline 11 & III & 17 & LOD/meningitis & $4-8$ & - \\
\hline 12 & Ia & 23 & EOD/bacteremia & $4-8$ & - \\
\hline 13 & III & 17 & EOD/meningitis & $4-8$ & - \\
\hline 14 & III & 17 & LOD/meningitis & $4-8$ & - \\
\hline 15 & $\mathrm{~V}$ & 453 & EOD/bacteremia & $4-8$ & - \\
\hline 16 & $\mathrm{~V}$ & 1 & LOD/bacteremia & $4-8$ & - \\
\hline 17 & III & 17 & EOD/meningitis & $4-8$ & - \\
\hline 18 & $\mathrm{Ib}$ & 10 & EOD/meningitis & $4-8$ & - \\
\hline 19 & Ia & 23 & LOD/bacteremia & $4-8$ & - \\
\hline 20 & III & 17 & LOD/meningitis & $4-8$ & - \\
\hline \multicolumn{6}{|l|}{ Reference strains } \\
\hline $2603 \mathrm{~V} / \mathrm{R}$ & $\mathrm{V}$ & 110 & ND & 32 & - \\
\hline A909 & Ia & 7 & ND & $8-16$ & - \\
\hline $\mathrm{COH} 1$ & III & 17 & ND & $8-16$ & - \\
\hline $18 \mathrm{RS} 21$ & II & 19 & ND & $4-8$ & - \\
\hline H36B & Ib & 6 & ND & $4-8$ & - \\
\hline 515 & Ia & 23 & ND & $32-64$ & - \\
\hline NEM316 & III & 23 & ND & $32-64$ & - \\
\hline NEM316 $\Delta \operatorname{cov} S R$ & III & 23 & ND & $>128$ & - \\
\hline NEM316 $\Delta c y l E$ & III & 23 & ND & $4-8$ & - \\
\hline NCTC10/84 & $\mathrm{V}$ & 26 & Septicemia & $>128$ & - \\
\hline
\end{tabular}

ND: not determined; (-): negative result.

\section{Acknowledgments}

We thank Prof Victor Nizet for providing the GBS strain NCTC10/84. We are grateful to Carmen Buchrieser for critical reading of the manuscript. E.M is funded by French National Agency (ANR Blanc Glyco-Path) attributed to S.D.

\section{References}

[1] K.M. Edmond, C. Kortsalioudaki, S. Scott, S.J. Schrag, A.K. Zaidi, S. Cousens, P.T. Heath, Group B streptococcal disease in infants aged younger than 3 months: systematic review and meta-analysis, Lancet 379 (2012) 547-556.

[2] A. Tazi, O. Disson, S. Bellais, A. Bouaboud, N. Dmytruk, S. Dramsi, M.Y. Mistou, H. Khun, C. Mechler, I. Tardieux, P. Trieu-Cuot, M. Lecuit, C. Poyart, The surface protein HvgA mediates Group B Streptococcus hypervirulence and meningeal tropism in neonates, J. Exp. Med. 207 (2010) 2313-2322.

[3] J.F. Bohnsack, A. Whiting, M. Gottschalk, D.M. Dunn, R. Weiss, P.H. Azimi, J.B. Philips 3rd, L.E. Weisman, G.G. Rhoads, F.Y. Lin, Population structure of invasive and colonizing strains of Streptococcus agalactiae from neonates of six U.S. Academic Centers from 1995 to 1999, J. Clin. Microbiol. 46 (2008) 1285-1291.

[4] N. Jones, K.A. Oliver, J. Barry, R.M. Harding, N. Bisharat, B.G. Spratt, T. Peto, D.W. Crook, Enhanced invasiveness of bovine-derived neonatal sequence type 17 Group B streptococcus is independent of capsular serotype, Clin. Infect. Dis. 42 (2006) 915-924.
[5] C.R. Phares, R. Lynfield, M.M. Farley, J. Mohle-Boetani, L.H. Harrison, S. Petit, A.S. Craig, W. Schaffner, S.M. Zansky, K. Gershman, K.R. Stefonek, B.A. Albanese, E.R. Zell, A. Schuchat, S.J. Schrag, Epidemiology of invasive Group B streptococcal disease in the United States, 1999-2005, J. Am. Med. Assoc. 299 (2008) 2056-2065.

[6] C. Poyart, H. Reglier-Poupet, A. Tazi, A. Billoet, N. Dmytruk, P. Bidet, E. Bingen, J. Raymond, P. Trieu-Cuot, Invasive Group B Streptococcal infections in infants, France, Emerg. Infect. Dis. 14 (2008) 1647-1649.

[7] J.M. Musser, S.J. Mattingly, R. Quentin, A. Goudeau, R.K. Selander, Identification of a high-virulence clone of type III Streptococcus agalactiae (Group B Streptococcus) causing invasive neonatal disease, Proc. Natl. Acad. Sci. U S A 86 (1989) 4731-4735.

[8] N. Jones, J.F. Bohnsack, S. Takahashi, K.A. Oliver, M.S. Chan, F. Kunst, P. Glaser, C. Rusniok, D.W. Crook, R.M. Harding, N. Bisharat, B.G. Spratt, Multilocus sequence typing system for Group B streptococcus, J. Clin. Microbiol. 41 (2003) 2530-2536.

[9] D. Maione, I. Margarit, C.D. Rinaudo, V. Masignani, M. Mora, M. Scarselli, H. Tettelin, C. Brettoni, E.T. Iacobini, R. Rosini, N. D'Agostino, L. Miorin, S. Buccato, M. Mariani, G. Galli, R. Nogarotto, V. Nardi Dei, F. Vegni, C. Fraser, G. Mancuso, G. Teti, L.C. Madoff, L.C. Paoletti, R. Rappuoli, D.L. Kasper, J.L. Telford, G. Grandi, Identification of a universal Group B streptococcus vaccine by multiple genome screen, Science 309 (2005) 148-150.

[10] S. Dramsi, E. Caliot, I. Bonne, S. Guadagnini, M.C. Prevost, M. Kojadinovic, L. Lalioui, C. Poyart, P. Trieu-Cuot, Assembly and role of pili in Group B streptococci, Mol. Microbiol. 60 (2006) 1401-1413.

[11] P. Lauer, C.D. Rinaudo, M. Soriani, I. Margarit, D. Maione, R. Rosini, A.R. Taddei, M. Mora, R. Rappuoli, G. Grandi, J.L. Telford, Genome analysis reveals pili in Group B Streptococcus, Science 309 (2005) 105. 
[12] R. Rosini, C.D. Rinaudo, M. Soriani, P. Lauer, M. Mora, D. Maione, A. Taddei, I. Santi, C. Ghezzo, C. Brettoni, S. Buccato, I. Margarit, G. Grandi, J.L. Telford, Identification of novel genomic islands coding for antigenic pilus-like structures in Streptococcus agalactiae, Mol. Microbiol. 61 (2006) 126-141.

[13] A.H. Nobbs, R. Rosini, C.D. Rinaudo, D. Maione, G. Grandi, J.L. Telford, Sortase A utilizes an ancillary protein anchor for efficient cell wall anchoring of pili in Streptococcus agalactiae, Infect. Immun. 76 (2008) 3550-3560.

[14] Y. Konto-Ghiorghi, E. Mairey, A. Mallet, G. Duménil, E. Caliot, P. TrieuCuot, S. Dramsi, Dual role for pilus in adherence to epithelial cells and biofilm formation in Streptococcus agalactiae, PLoS Pathog. 5 (2009) e1000422.

[15] H.C. Maisey, M. Hensler, V. Nizet, K.S. Doran, Group B streptococcal pilus proteins contribute to adherence to and invasion of brain microvascular endothelial cells, J. Bacteriol. 189 (2007) 1464-1467.

[16] A. Banerjee, B.J. Kim, E.M. Carmona, A.S. Cutting, M.A. Gurney, C. Carlos, R. Feuer, N.V. Prasadarao, K.S. Doran, Bacterial pili exploit integrin machinery to promote immune activation and efficient bloodbrain barrier penetration, Nat. Commun. 2 (2011) 462.

[17] R. Al Safadi, L. Mereghetti, M. Salloum, M.F. Lartigue, I. VirlogeuxPayant, R. Quentin, A. Rosenau, Two-component system RgfA/C activates the fbsB gene encoding major fibrinogen-binding protein in highly virulent CC17 clone Group B Streptococcus, PLoS One 6 (2011) e14658.
[18] C. Danne, J.M. Entenza, A. Mallet, R. Briandet, M. Debarbouille, F. Nato, P. Glaser, G. Jouvion, P. Moreillon, P. Trieu-Cuot, S. Dramsi, Molecular characterization of a Streptococcus gallolyticus genomic island encoding a pilus involved in endocarditis, J. Infect. Dis. 204 (2011) 1960-1970.

[19] V. Nizet, R.L. Gibson, E.Y. Chi, P.E. Framson, M. Hulse, C.E. Rubens, Group B streptococcal beta-hemolysin expression is associated with injury of lung epithelial cells, Infect. Immun. 64 (1996) 3818-3826.

[20] N. Bisharat, D.W. Crook, J. Leigh, R.M. Harding, P.N. Ward, T.J. Coffey, M.C. Maiden, T. Peto, N. Jones, Hyperinvasive neonatal Group B streptococcus has arisen from a bovine ancestor, J. Clin. Microbiol. 42 (2004) 2161-2167.

[21] C.A. Huber, F. McOdimba, V. Pflueger, C.A. Daubenberger, G. Revathi, Characterization of invasive and colonizing isolates of Streptococcus agalactiae in East African adults, J. Clin. Microbiol. 49 (2011) $3652-3655$.

[22] M. Brochet, E. Couve, R. Bercion, J.M. Sire, P. Glaser, Population structure of human isolates of Streptococcus agalactiae from Dakar and Bangui, J. Clin. Microbiol. 47 (2009) 800-803.

[23] K.S. Doran, G.Y. Liu, V. Nizet, Group B streptococcal beta-hemolysin/ cytolysin activates neutrophil signaling pathways in brain endothelium and contributes to development of meningitis, J. Clin. Invest. 112 (2003) 736-744. 